\title{
Parto Também é Assunto de Homens: Uma Pesquisa Clínico-Qualitativa Sobre a Percepção dos Pais Acerca de Suas Reações Psicológicas Durante o Parto
}

\author{
Aline Grazieli de Oliveira* \& Rosanna Rita Silva \\ Universidade Estadual do Centro-Oeste (UNICENTRO), Irati, Brasil
}

\begin{abstract}
RESUMO
O presente estudo discute a presença do pai na sala de parto. Trata-se de pesquisa desenvolvida por meio do método clínico qualitativo e objetivou identificar a percepção que os pais têm acerca das reações psicológicas vivenciadas durante o parto. Verificou-se por parte deles uma mobilização para procurar informações sobre o parto e também acerca da gestação por meio de fontes diversas. A entrada e permanência na sala de parto foram percebidas como impactantes, e os sentimentos vivenciados durante este processo relatados como de ambivalência. Além disso, evidenciou-se que essa participação foi entendida por eles como fundamental para a construção da relação pai- filho, da mesma forma que apontou para uma posição mais aberta dos pais em relação a sua participação no parto.

Palavras-chave: parto; hospital; relação pai-filho.
\end{abstract}

\section{ABSTRACT \\ Childbirth Is Also a Men's Issue: A Clinical-Qualitative Research About the Father's Perception About Their Psychological Reactions During Delivery}

This study discusses the father's presence in delivery rooms. The research was based on the clinicalqualitative method and it aimed to identify the fathers' perceptions of their psychological reactions during childbirth. The fathers were concerned in looking for information about the delivery and also about the pregnancy itself in several sources. The admission and presence in the delivery room were perceived as disturbing, and the feelings experienced during this process were classified as ambivalent ones. Moreover, this participation was considered by them as essential for the building of the fatherchild relationship, and it also pointed to a more open-hearted position concerning their participation in the delivery.

Keywords: childbirth; hospital; father-child relationship.

O processo de gerar um filho abrange vivências comuns partilhadas, mas também envolve implicações diferenciadas para a mulher e para o homem. A gravidez corresponde ainda a momentos cruciais para a saúde do bebê e o estabelecimento das relações no âmbito da tríade mãe, pai e filho. O momento do parto particularmente pode ser considerado crítico na medida em que corresponde a uma passagem irreversível e de grande vulnerabilidade. Por não ser absolutamente previsível em termos de data, horário, circunstâncias e intercorrências possíveis, remete a falta de controle da situação por parte dos pais. Além disso, está vinculado ao internamento hospitalar com todas as implicações do ingresso nesta instituição.

No que se refere à parturiente, estudos como de Nakano, Silva, Beleza, Stefanello e Gomes (2007) apontam que a presença do acompanhante na sala de parto além de propiciar apoio emocional, também oferece tranquilidade e incentivo. No mesmo sentido, Motta e Crepaldi (2005) afirmam que o acompanhante oferece confiança, segurança e conforto. Perdomini e Bonilha (2011), por sua vez, vislumbram que quando

\footnotetext{
Endereço para correspondência: Aline Grazieli de Oliveira - alineoliveira_psi@ hotmail.com.
} 
o pai da criança é o acompanhante promove efeitos positivos no relacionamento familiar, principalmente na formação do vínculo pai-bebê. Além disso, essas autoras asseveram que tal acompanhamento pode diminuir as intercorrências desse momento, devido à confiança proporcionada pelo acompanhante.

De acordo com o Ministério da Saúde (2001), a presença do companheiro ou de outra pessoa escolhida pela gestante para assisti-la na hora do parto, faz parte de um suporte psíquico e emocional que proporciona alívio do medo e da ansiedade. Conforme a Lei n. 11.108, de 7 de abril de 2005, regulamentada pela Portaria número 2.418/GM de 2 de dezembro de 2005, fica assegurado que a parturiente tem o direito de contar com o apoio de um acompanhante no momento do parto, em qualquer hospital que preste serviços ao Sistema Único de Saúde (Lei n. 11.108/2005).

Em relação ao apoio oferecido pelo pai durante o parto, Motta e Crepaldi (2005) evidenciaram três formas de interação denominadas de presença passiva, de referência familiar e presença ativa. A presença passiva é caracterizada pelo não envolvimento efetivo no processo de parto e pela dificuldade de se relacionar com a parturiente neste momento, evidenciando grande ansiedade e necessitando mesmo sair do ambiente frequentemente. A referência familiar pode ser descrita como a maior disponibilidade por parte dos acompanhantes em apoiar a parturiente com a orientação constante da equipe sobre o que pode ser feito para ajudar nesse momento. Já a presença ativa refere-se ao oferecimento de segurança e conforto de forma autônoma e espontânea, por meio de palavras de encorajamento, elogios e mesmo pelo desenvolvimento de atividades de apoio como acompanhar a parturiente na deambulação, ajudá-la a mudar de posição, segurar a sua mão e lhe oferecer carinho.

Além dessa distinção na forma de apoio, Freitas, Fernandes e Vaz (2007) classificam as atividades realizadas pelos acompanhantes durante o parto em quatro categorias: suporte emocional, que consiste em encorajar, tranquilizar e estar presente continuamente; medidas de conforto físico como massagens e métodos não farmacológicos para alívio da dor; suporte de informação por meio de orientações, instruções e aconselhamento e, defesa, que consiste em interpretar os desejos do casal frente ao agir em seu favor.

No que diz respeito à vivência do homem, Carvalho (2003) e Freitas et al. (2007) afirmam que ela é efeti- vamente importante para fortalecer os vínculos familiares, principalmente entre pai-bebê. Da mesma forma, essa participação no nascimento implica uma oportunidade do pai se sentir parte inclusiva do processo de gestação e chegada do filho (Carvalho, 2003).

Tendo em conta estas questões, a presente pesquisa aborda a presença do pai na sala de parto. Acredita-se que além de ser um direito da mulher, a questão consiste também em um direito do homem. E nessa medida é fundamental a construção de conhecimentos acerca de sua ótica particular. O objetivo, então, é identificar a percepção que os pais têm acerca das reações psicológicas vivenciadas durante o parto.

Como pesquisadora da constituição da paternidade, este assunto - o da presença do pai durante o nascimento de um filho - instiga a buscar referencial teórico no que concerne à problemática da relação paifilho já no nascimento. Trata-se apenas de um recorte, de uma parcela frente à complexidade que o tema envolve.

\section{ASPECTOS METODOLÓGICOS}

O desenvolvimento da pesquisa iniciou após o recebimento de aprovação do Comitê de Ética em Pesquisa com Seres Humanos da Universidade Estadual do Centro-Oeste, sob o protocolo número 04540/2009.

Os participantes foram escolhidos por meio de uma busca aleatória, em que a pesquisadora entrou em contato com diversas pessoas (com vínculo e sem vínculo prévio) a fim de verificar se estas conheciam homens que tivessem vivenciado a situação estudada. Como critérios de inclusão estavam a necessidade de ter mais de 18 anos; ter acompanhado o parto do filho em hospital há no máximo dois anos para que não houvesse diferença significativa no que se refere à data da experiência.

Desse modo, cinco homens participaram da pesquisa, sendo que estes possuíam idades entre 22 e 36 anos. Foram selecionados apenas cinco participantes devido à dificuldade em encontrar homens que tivessem participado do nascimento do filho. Uma hipótese para essa dificuldade pode estar no fato de que a cidade na qual a pesquisa foi realizada possui apenas um hospital, além de ser considerada uma cidade interiorana. Outra hipótese é de que mesmo a conduta de presenciar o nascimento de um filho constituir-se em um direito do homem, este ainda não esteja sendo visto como tal. 
Para preservação das identidades dos mesmos, aqui serão chamados pelos nomes fictícios de Alessandro, Bernardo, Cassiano, Danilo e Emanuel. Todos aceitaram participar por meio da assinatura do termo de consentimento livre e esclarecido.

Como instrumento, foi utilizada a entrevista semiestruturada, e o método empregado o clínico-qualitativo de conteúdo, que busca dar interpretações aos significados expostos pelos indivíduos sobre diversos fenômenos relacionados ao campo saúde/doença, conforme o define Turato (2003). A primeira fase do trabalho foi análise dos conteúdos obtidos em cada uma das entrevistas e depois do conjunto delas, com a leitura flutuante das informações, não sendo priorizado inicialmente nenhum elemento.

O momento seguinte foi o de categorização, onde foram classificados os elementos constitutivos de um conjunto em razão da repetição e relevância dos elementos conforme cita Bardin (2004).

\section{RESULTADOS}

A partir da entrevista semiestruturada pode-se conhecer um pouco sobre a história dos participantes.

\section{Alessandro}

Alessandro, trinta e seis anos, possui o ensino médio completo e trabalha como gerente de Tecnologia Industrial. É casado e têm dois filhos, o primeiro com dois anos e o segundo com três meses e duas semanas. Presenciou somente o parto do segundo filho quando a esposa encontrava-se com trinta e quatro semanas de gestação, o qual ocorreu por meio do parto normal.

Acompanhou a gestação desde a primeira semana, participando das consultas pré-natais. Já havia assistido outros partos, em uma aula de primeiros socorros exibida pela empresa em que trabalhou anteriormente, ao passo que estes continham informações básicas a respeito do nascimento.

De acordo com Alessandro, o hospital não lhe forneceu informação específica alguma sobre o parto. Porém, lhe foram dadas orientações acerca da sua presença na sala de parto e como poderia contribuir. Expuseram-lhe que deveria ajudar a companheira durante a respiração e contagem das contrações, além de segurar sua mão. Além disso, também lhe disseram que tinha que ficar ajudando, que por mais que tenha mais enfermeiras o pai é fundamental na hora pra ajudar a mãe.
Mencionou que antes de entrar na sala de parto estava eufórico, com aquela coisa assim nossa! Vai nascer a qualquer momento! No entanto, pensou que ali você tem que ficar calmo. Ali não adianta... vai nascer a qualquer momento, mas tem que ficar ali dando força, conversando. Ao entrar sentiu-se tenso, mas ainda assim eufórico.

Alessandro disse que durante a realização do parto sentiu" uma alegria muito grande [...] de repente o teu filho nasce [...] Então você fica nossa! Muito legal, olha é indescritível você vê seu filho nascer. Para lidar com esses sentimentos, comentou ter feito força junto com a esposa e logo que o bebê nasceu telefonou para os familiares e amigos para comunicar o nascimento do filho. Expôs que na hora entendeu essas reações como de felicidade e alegria e que por este motivo ligou para todos. E hoje entende que todo pai que tá presente sente, né? O filho é uma parte do teu DNA que tá ali, que vai crescer, que vai estudar.

\section{Bernardo}

Bernardo, vinte e cinco anos, possui o ensino superior e trabalha como contador. É casado e tem somente um filho, de um mês e duas semanas. Este nasceu na trigésima quarta semana por meio de um parto normal.

Ao longo da gestação foi se preparando para estar presente no parto do filho. Participou de algumas consultas pré-natais, faltando somente em duas, referentes à amamentação, porque não deu pra eu sair do trabalho. Mas acho que a amamentação é mais pra mãe. Pesquisou em sites na internet informações sobre massagens e técnicas para fortalecimento dos músculos envolvidos, tipos de parto e sua recuperação, bem como utilizou informações obtidas por meio das consultas pré-natais e do contato com outras mães. A elas, perguntava o motivo pelo qual escolheram realizar determinado parto e como tinha ocorrido. Apesar de ter se mobilizado no sentido de saber a respeito, Bernardo entendeu que não se preparou especificamente para o parto e ainda referiu-se a ele como algo que não tem como prever direito, como dizer o que vai acontecer.

O hospital onde o parto foi realizado lhe forneceu informações apenas acerca da sua presença na sala de parto. No entanto, isso ocorreu indiretamente por meio da esposa, que trabalha neste local. Informaram-lhe que se não participasse das consultas do pré-natal não estaria preparado para presenciar o nascimento do 
filho. Da mesma forma, também lhe instruíram a permanecer calmo e ao lado da esposa, sempre a apoiando.

Antes de entrar na sala de parto ficou ansioso. Segundo Bernardo: eu esperei por este momento, eu não queria que acabasse. Eu queira que demorasse mais. Além disso, mencionou que estava tremendo e que sentiu uma adrenalina. E ao mesmo tempo em que queria que acabasse logo também desejava que não terminasse tão rápido.

Disse ter reprimido esses sentimentos para si, pois entendeu que não podia ficar nervoso. "Então eu pensei que eu tava ali e ia ajudar, incentivar e eu abracei ela dando força. Eu fazia força junto com ela", referindo-se à esposa. Ao entrar na sala de parto sentiu um misto de ansiedade, medo e certeza. Ansiedade, pois esperamos muito tempo para aquele momento e ele estava ali, tinha chegado a hora e agora não podíamos mais voltar; medo pelo meu filho que estava prestes a conhecer, e eu ansiava muito para ver ele saudável; e certeza que estava acabando e logo estaria tudo bem, apesar de nunca mais nada ser igual nas nossas vidas tudo seria ótimo com certeza. Porém, disse não dá pra dizer o que eu senti, porque na hora não que você não sente, mas você não fica pensando no que tá sentindo.

Durante o parto sentiu medo, desconforto e ansiedade para que tudo acabasse logo e bem. Descreveu ainda o sentimento de impotência naquele momento, onde você pensa em poder fazer parte mais intensamente daquele momento, poder ajudar de alguma forma mais ativa, e você vê que está de mãos atadas e tudo o que você pode fazer é dar força. É um momento tão pequeno e tão eterno ao mesmo tempo. Não se consegue nem ao menos rezar, nem pensar [...] Você se diminui e toda a importância e atenção vai para eles e logo depois o neném rouba a cena. A partir daí tudo roda em torno dele.

Em relação ao modo como lidou com suas reações disse: "eu não olhei pra ela, não olhei por onde tinha saído, porque esse é o papel do médico. Eu tinha que apoiar, e achei que se eu olhasse podia trazer algumas situações complicadas". Naquele momento entendeu que suas reações foram automáticas, mas ficou contente por ter aguentado sem vacilar. No entanto, acho que fui meio frio [...] mas acho que é só por que eu sabia que estava fazendo tudo que podia por ela. Acho que fiz o que tinha que ser feito da melhor forma possivel.
Quanto ao modo como entende suas reações hoje expôs que fez o melhor que poderia ter feito, apoiou, incentivou, permaneceu ao lado, tentou ficar calmo. Além disso, é uma forma de eu saber como me comporto em ocasiões de risco ou de necessidade. Eu já me conhecia e gosto de ser assim, nesses momentos às vezes é bom ser frio, porque se pensa melhor de quando está desesperado.

\section{Cassiano}

Cassiano tem vinte e dois anos e cursa o ensino superior. É casado e tem um filho de um ano e três meses. O parto ocorreu por meio de um procedimento cesáreo aos nove meses. Participou de algumas das consultas pré-natais, em razão de trabalhar fora da cidade não pode acompanhar todas as consultas. No entanto, mesmo não estando perto fisicamente, sempre que podia telefonava para perguntar como estava o desenvolvimento do bebê.

Disse não ter se preparado para assistir o parto do filho, visto que queria deixar que o momento acontecesse sem criar expectativas. No entanto, entende que o fato de estudar um curso da área da saúde lhe ajudou a enfrentar a situação. Segundo ele, não criei expectativas pra esse dia, mas já me preparei falando que eu que ia assistir. E, acrescentou: confesso pra você que é um sentimento que só quem passa que pode contar como que é. E se eu contar pra você eu não vou estar conseguindo passar pra você tudo o que eu senti no momento, porque é uma emoção inexplicável.

Já no hospital, antes de começar o parto a enfermeira-chefe lhe forneceu algumas informações acerca da sua presença na sala. Esta lhe falou que deveria permanecer na área delimitada pelo médico e andar por um caminho que não atrapalhasse a equipe. Poderia conversar com sua companheira, mas não poderia interferir nos procedimento que a equipe realizava. Seriam permitidos questionamentos, mas no caso de não receber resposta seria porque os médicos estariam concentrados na cirurgia e, caso se sentisse mal, permaneceria no local até o término do parto e só então seria socorrido. Porém sobre o parto nada foi lhe passado.

Antes de entrar na sala viveu a expectativa do momento, a qual se referiu como sendo a esperança de que tudo ocorresse bem com a companheira e com o bebê, por meio de um procedimento correto. A maneira como lidou com este sentimento foi com coragem, [pois] eu não sabia se estava ou não preparado psicologicamente [...] talvez por estar mais ou menos na 
área que eu tenho mais contato com esse tipo de coisa, talvez isso tenha me facilitado.

Quanto ao modo como entendeu as reações mobilizadas durante o momento do parto de seu filho, Cassiano disse que é impossível entendê-las, apenas sentilas. Sentiu-as de maneira especial [...] foi um medo prazeroso [...] uma expectativa prazerosa. Talvez tudo foi prazeroso porque o momento era prazeroso, porque era o nascimento do meu primeiro filho. Ao entrar na sala, o coração acelerou, os batimentos aceleraram, o corpo ficou quente e começou a tremedeira, mas à medida que eu ia vendo o procedimento acontecendo eu fui ficando mais calmo. Apreensivo pra ver como que seria ele [...] A entrada na sala é um negócio impactante, porque você tá num local [...] que você sabe que dali vai sair o resultado futuro da tua vida, do teu filho, da tua família [...] como se fosse a manjedoura de Jesus, é o espaço que vai ficar simbolizado na tua mente.

Durante o parto vivenciou um sentimento de expectativa, apreensão e de preocupação, mas tinha uma expectativa de que tudo iria dar certo, mas também sentia uma apreensão e preocupação por estar ali presente. Ele sentia-se como um intruso, e por isso tinha a sensação de estar atrapalhando a equipe. Porém estava certo de que não atrapalhou em nada, visto que permaneceu no lugar determinado.

Cassiano relatou que guardou esses sentimentos para si, tentando não transparecer suas reações, de modo que não chorou nem desmaiou. Naquele momento entendeu suas reações como automáticas, aonde elas vão acontecendo, vão se empilhando [...] não tem tempo de pensar nas reações você vai agindo por impulsos [...] o pessoal vai dando as indicações e você vai acatando. Acrescentou que é uma coisa única de momento que não tem como ser descrita, é uma sensação jamais sentida antes e que não pode ser comparada com as demais. Entende-as hoje como um momento único na relação pai e filho, talvez o mais importante nessa relação. Assim, ele aconselha seus amigos a presenciarem o nascimento de seus filhos. No entanto, disse que se não tivesse ido não estaria arrependido, pois não teria sentido o que sentiu e assim não saberia como é ver o nascimento de um filho.

\section{Danilo}

Danilo tem vinte e oito anos, possui o ensino superior incompleto e trabalha como vigia. É casado e tem um filho de cinco meses. O parto aconteceu quando a esposa encontrava-se com trinta e duas semanas de gestação, de modo que inicialmente foi induzido ao parto normal, porém por não haver dilatação os médicos tiveram que realizar uma cesariana. Além disso, seu filho precisou permanecer internado na Unidade de Terapia Intensiva Neonatal por algum tempo (aproximadamente um mês).

Danilo permaneceu durante todo o tempo de trabalho de parto junto com sua esposa. Relatou que não pôde ir às consultas pré-natais por indisponibilidade de horário, mas sempre levava ao serviço as ecografias para vê-las melhor. Preparou-se para o parto pesquisando em sites da internet. Nestes, pesquisou sobre tipos de parto e sua recuperação, prematuridade, complicações no parto e formação do bebê. Segundo ele, já tava virado num médico ali já. Já tava sabendo tudo. Relatou não ter recebido informações por parte do hospital, apenas foi orientado a não encostar-se à sua companheira.

Em relação ao modo como se sentiu antes de entrar na sala de parto disse: eu não sabia o que estava acontecendo com ela, ficava bem louco lá fora. Dá vontade de ir lá dentro ver o quê que tá acontecendo. Comentou que não deixou transparecer para sua esposa o que estava sentindo, pois precisava dar força a ela, a única coisa que poderia fazer neste momento. Quanto à forma como essas reações foram entendidas, Danilo disse: Ah! Sei lá, não dá pra falar. As coisas acontecem muito ligeiro. [...] Eu coloquei na minha cabeça, não, eu tenho que dar força pra ela, que era só eu que tava lá, ninguém podia entrar, só eu [...] Não saí do lado dela nem um minuto, todo dia fiquei com ela". Ao entrar na sala, me amoleceu as pernas, mas não desmaiei, fui firme. É uma sensação assim muito estranha, porque você sabe que vai entrar ali e vai ver teu filho pela primeira vez. Estava nervoso, mas eu não queria demonstrar pra ela [...] eu queria dar força. Acrescentou que já não aguentava mais, estava exausto devido ao tempo de internação da esposa. Durante o parto sentiu muito medo de que algo de errado acontecesse com a esposa e filho, de que o machucassem, visto que se tratava de um parto de risco. Além disso, sentiu também desespero devido aos movimentos que o médico fazia serem muito fortes e a passagem do tempo sem que o nascimento ocorresse. Expôs que pensou em Deus e que colocou a vida do filho em suas mãos, que antes do início do parto pediu ao anjo da guarda do filho para que cuidasse dele. Complementou que foi atendido. 
Naquele momento, você não pensa, não raciocina. O teu foco é tão grande no neném que você não pára pra pensar no medo. Você sente aquele medo, mas não consegue tirá-lo de lá. [...] mas ele só está ali para te atrapalhar. No entanto, Danilo comentou que hoje ri de tudo o que passou. Porém, considera este como o parto mais triste do mundo, principalmente porque seu filho teve que ficar internado, o que o impossibilitou que cuidasse dele.

\section{Emanuel}

Emanuel tem trinta e seis anos, possui o ensino médio completo e trabalha como gerente de vendas. É casado e tem dois filhos, uma menina com quinze anos e um menino de um mês e sete dias. Presenciou somente o parto do segundo filho, o qual foi realizado quando a esposa encontrava-se com trinta e seis semanas de gestação, por meio de uma cesárea.

Emanuel acompanhou a esposa na realização das ecografias. Em relação à forma como se preparou para o parto disse que havia apenas ouvido falar e tinha visto em vídeos, mas que nunca tinha imaginado que um dia participaria do parto de seu filho. No entanto, relatou que se preparou bem, pois conversou com o médico e este lhe explicou como seria o parto. Além disso, só esperava coisas boas.

Comentou ter recebido informações por parte do hospital acerca da anestesia, duração do parto, locais em que poderia permanecer durante a realização do parto, como permanecer do lado da parturiente ou assistindo a retirada do bebê. Antes de entrar na sala de parto sentiu ansiedade, a qual fazia com que ele percebesse o tempo como mais rápido, de modo que havia passado apenas alguns minutos, mas tinha a sensação de ter esperado horas até entrar na sala. Disse ter guardado para si para não demonstrar a sua esposa, tentou ficar tranquilo, rezou e pensou positivo que tudo daria certo. Além disso, comentou que por não saber o que estava acontecendo lá dentro ficava imaginando o que se passava e pensando em sua experiência com a filha mais velha. Nesse momento relembrou como havia passado a gravidez, a qual causou dores a sua esposa, assim ele pensava que quando o filho nascesse tudo acabaria. Ao entrar na sala sentiu um nervosismo, porque você tá ali diante de tudo, aqueles equipamentos [...] comecei a suar frio [...] a mão já começou assim meio a tremer [...] Então eu entrei bem nervoso, mas controlado pra não passar pra ela. Durante o parto também estava ansioso e uma ambivalência apareceu nos seus relatos, ambivalência esta que misturava ansiedade e alegria. Emanuel também disse ter a sensação de que havia demorado mais tempo do que realmente aconteceu. Depois do nascimento, ficou mais leve, com a sensação de dever cumprido e passou então a imaginar o futuro.

Em relação à maneira como entendeu suas reações naquele momento disse não tê-las compreendido devido não estarem presentes em seu cotidiano. E hoje se pergunta o porquê ficou tão ansioso naquele momento e entende que se precisasse passar novamente, com certeza hoje estaria mais bem preparado e ficaria mais calmo.

\section{DISCUSSÃO}

As categorias de análise obtidas por meio das entrevistas foram referentes às percepções que os homens tiveram acerca de três momentos: sobre o modo como eles se prepararam durante os meses da gestação para participar do parto de sua companheira; sobre a maneira com que perceberam os momentos que antecederam imediatamente o parto; e, sobre a percepção que tiveram do momento do parto.

\section{Como os pais se prepararam, durante a gestação, para acompanhar o parto?}

A pesquisa evidenciou uma mobilização por parte dos pais entrevistados em se preparar para o parto já no decorrer da gestação. Nesse sentido, utilizaram diversos meios para obter informações sobre esse momento como a busca na rede mundial de computadores, programas de orientação a gestante, presença nas consultas pré-natais, vídeos e o contato direto com gestantes. Por meio desses recursos diversas informações foram buscadas a respeito da gravidez e do parto. Foram pesquisados os tipos de parto e sua recuperação, massagens e prematuridade bem como possíveis complicações e formação do bebê. Tal procura por informações pode ser interpretada como um indício de mudanças, como verificado por Piccinini, Silva, Gonçalves, Lopes e Tudge (2004), em sua pesquisa sobre o envolvimento paterno. Para os autores, o desejo de assistir o parto ainda é pouco visado pelos pais, uma vez que este ainda é visto como um evento essencialmente feminino, onde a participação do pai não encontra lugar.

Contrapondo então os achados de Piccinini et al. (2004), a presente pesquisa demonstrou uma curiosi- 
dade por parte dos participantes em se preparar para a situação do parto. Nesse sentido, pode-se afirmar que o parto, bem como a gestação, está aos poucos sendo inserido no imaginário masculino, mobilizando assim o desejo de conhecer esse evento e de participar dele. Por outro lado, apesar de todos os pais entrevistados terem buscado informações sobre o evento do parto, eles perceberam tal preparação de modo peculiar. Nesse sentido, por mais que se mobilizaram para buscar informações parece que estas não foram suficientes para garantir a segurança dos pais quanto a sua preparação. Bernardo e Cassiano, por exemplo, relataram ter vivenciado o sentimento de não ter se preparado para o parto. Esta vivência pode ser interpretada como um reflexo da insegurança desses pais em relação ao que deveriam esperar do momento do parto.

Como descrito por Maldonado e Dickstein (2010) o parto possui um caráter de imprevisibilidade, o qual parece estar presente no imaginário dos participantes da presente pesquisa. Nas falas de Bernardo tal caráter de imprevisibilidade pôde ser claramente visualizado quando ele disse que o parto é "algo que não tem como prever direito, como dizer o que vai acontecer".

Ao contrário do sentimento referendado por Bernardo e Cassiano, o sentimento vivenciado por Danilo de se afirmar como quase médico pode ser interpretado como uma forma encontrada por ele para assegurar-lhe segurança. Desse modo, ao estabelecer esta referência, Danilo está se colocando no nível daquele que mais sabe sobre aquela situação ou ainda, com aquele que tem maior controle sobre ela.

\section{Como os pais perceberam os momentos imediatamente antecedentes ao parto?}

Em relação à percepção dos momentos que antecederam imediatamente o parto, a presente pesquisa demonstrou que cada pai vivenciou sentimentos particulares de ansiedade, euforia, expectativa do nascimento e curiosidade. Além desses sentimentos, reações físicas também estiveram presentes nesse momento, como tremer, sentir a adrenalina subir, suar e sentir aceleração dos batimentos cardíacos.

Outro sentimento que permeou os momentos de espera antes da entrada na sala de parto foi o de estar enlouquecendo, como foi a expressão utilizada por Danilo por não saber o que acontecia dentro da sala de cirurgia. Esta vivência vai ao encontro dos achados de Espírito Santo e Bonilha (2000), as quais salientam que quando os pais são impedidos de presenciar o nascimento de seus filhos é comum que haja sofrimento, desespero, angústia e ansiedade por ter que esperar do lado de fora. Para elas ainda, quando presenciam o parto, os pais têm a possibilidade de sentirse parindo seus filhos.

Embora os pais tenham vivenciado sentimentos peculiares, um fato interessante foi que ambos consideraram necessário não expressar as emoções vividas para que elas não fossem percebidas pela parturiente. Assim, julgaram como primordial manter a calma nesse momento. Essa necessidade de reprimir os sentimentos já foi apontada por Tarnowski, Próspero e Elsen (2005). Conforme estas autoras, o contexto atual tem exigido dos homens uma postura diferente daquela que aprenderam e isto provoca sentimentos contraditórios e ambivalentes. Culturalmente, foi lhes ensinado que não é permitido um homem expressar seus sentimentos e, neste sentido, resta-lhes apenas a possibilidade de silenciar-se frente ao que é interpretado como instantes de tamanha fragilidade para a mulher. Pode-se acrescentar que o momento também é de muita fragilidade para o homem.

Além dessas percepções, a pesquisa também demonstrou que para os pais não é possível entender as reações sentidas nos momentos que antecederam $o$ parto, ao passo que elas podem ser apenas sentidas. Isso pode ser visualizado nas falas de Bernardo quando ele diz que não dá pra dizer o que eu senti, porque na hora não que você não sente, mas você não fica pensando no que tá sentindo.

Em relação à entrada na sala de parto, ainda na segunda categoria, esta foi entendida como algo impactante, como fala Cassiano: a entrada na sala é um negócio impactante, porque você tá num local [...] que você sabe que dali vai sair o resultado futuro da tua vida, do teu filho, da tua família [...] como se fosse a manjedoura de Jesus, é o espaço que vai ficar simbolizado na tua mente.

\section{Como os pais perceberam o momento do parto?}

No que se refere à conduta dos pais no momento do parto, a presente pesquisa verificou que os pais vivenciaram sentimentos de alegria, medo, desconforto, desespero, ansiedade, sentimento de expectativa/esperança, apreensão e preocupação. Tais sentimentos não foram vivenciados de maneira separada, na medida em que os pais relataram vivenciá-los de forma ambivalente, onde sentiam-se alegres pelo nascimento, 
porém ao mesmo tempo sentiam medo de que ocorresse alguma intercorrência no parto.

Esses sentimentos já foram descritos por Storti (2004) e Tedesco et al. (2004) ao afirmarem que ao participar do nascimento do filho o homem vivencia diversos sentimentos, como felicidade, ansiedade e medo. Os sentimentos de medo e de desespero também foram relatados pelos pais entrevistados, e estiveram voltados tanto para a parturiente quanto para o bebê. Além disso, também esteve presente o desconforto em relação aos movimentos prestados pelos médicos, os quais foram entendidos como bruscos.

Nas falas de Bernardo, ainda apareceu a sensação de impotência, onde você pensa em poder fazer parte mais intensamente daquele momento, poder ajudar de alguma forma mais ativa, e você vê que está de mãos atadas e tudo o que você pode fazer é dar força. É um momento tão pequeno e tão eterno ao mesmo tempo. Não se consegue nem ao menos rezar, nem pensar [...] Você se diminui e toda a importância e atenção vai para eles, e logo depois o neném rouba a cena. A partir daí tudo roda em torno dele. $\mathrm{O}$ sentimento de impotência evidenciado aqui pelo pai entrevistado já foi relatado anteriormente por Raphael-Leff (1997). De acordo com este autor, o homem pode experimentar a sensação de impotência e frustração principalmente diante da dor sentida pela parturiente. Interessante que na presente pesquisa esse acontecimento ficou inclusive explícito na fala de Bernardo ao dizer que estava de mãos atadas.

Nesse momento, o da realização do parto, também houve a necessidade de não expressar sentimentos. $\mathrm{Da}$ mesma forma, elas foram entendidas como reações automáticas, que vão acontecendo, vão se empilhando [...] não tem tempo de pensar nas reações você vai agindo por impulsos (Cassiano).

Ainda sobre os sentimentos vivenciados no momento do parto, Bernardo demonstrou ter se preocupado com a sua postura, no sentido de que percebeu que não estava se envolvendo tanto com o momento. Em seu discurso surge "acho que fui meio frio [...] mas acho que é só por que eu sabia que estava fazendo tudo que podia por ela. Acho que fiz o que tinha que ser feito da melhor forma possível". Acrescenta que tal situação ainda the possibilitou perceber como reage em tais situações, uma vez que é uma forma de eu saber como me comporto em ocasiões de risco ou de necessidade. Eu já me conhecia e gosto de ser as- sim, nesses momentos às vezes é bom ser frio, porque se pensa melhor de quando está desesperado.

Pode-se relacionar esta fala com o fato de não ser permitido ao homem expressar-se emocionalmente. Tal fato já foi discutido na presente pesquisa, porém parece ser algo de grande relevância, uma vez que se faz presente marcadamente nos relatos dos pais entrevistados. Além disso, mostra que o evento de ter acompanhado o parto permitiu aos pais que eles entrassem em contato com reações que talvez não pudessem ser vividas por meio de outra experiência.

Outro sentimento que permeou a vivência dos pais na sala de parto foi a sensação de ser um intruso naquele local, o que corrobora a pesquisa de Perdomini e Bonilha (2011). Cassiano disse que embora soubesse que não estava atrapalhando, se sentiu como um intruso. Segundo esse pai: você se sente meio que atrapalhando [...] que você tá sendo um intruso ali é grande. Ainda, Emanuel relatou um alívio após a retirada do bebê do corpo da mãe.

Por meio dessa pesquisa também foi possível conhecer, mesmo que de maneira aproximada, o modo como o hospital lida com essas situações. Pôde-se perceber que para nenhum dos participantes foi prestada qualquer informação a respeito do parto. Exceto para Emanuel, onde o anestesista explicou sobre a anestesia e suas possíveis reações e a enfermeira lhe informou sobre o tempo de duração do parto. No entanto, para a maioria dos pais, foi oferecido informações apenas acerca da presença deles na sala de parto. A eles foi transmitido sobre as formas como poderiam auxiliar a parturiente, na respiração, contagem de contrações; comportamentos de apoio, como segurar a mão, incentivar; e, delimitação da área onde poderiam permanecer na sala de parto. Exceto para Danilo, o qual disse ter sido apenas orientado a não encostar-se à sua companheira. Por outro lado, uma conduta de valorização da presença do pai na sala de parto por parte da equipe pode ser vista na fala de Alessandro, onde uma das enfermeiras lhe falou que tinha que ficar ajudando, que por mais que tenha mais enfermeiras o pai é fundamental na hora pra ajudar a mãe.

Para Cassiano foi dada a possibilidade de levantar questionamentos na sala de parto, porém justificando possíveis negativas de respostas. Ele relata que seriam permitidas perguntas, mas no caso de não receber resposta seria porque os médicos estariam concentrados na cirurgia e, caso se sentisse mal, permaneceria 
no local até o término do parto e só então seria socorrido. Porém sobre o parto nada foi lhe passado.

Esse tipo de conduta por parte da instituição de não oferecer informações aos pais acompanhantes contraria a posição de Perdomini e Bonilha (2011), uma vez que para elas inserir o pai na sala de parto sem antes oferecer orientação pode fazer com que a ansiedade presente neste momento aumente. Assim, ao invés de auxiliar na vivência desse evento novo e diferente, como o nascimento de um filho, o hospital estaria dificultando tal experiência. Essa opinião também é defendida por Motta e Crepaldi (2005), ao passo que apontam o esclarecimento de dúvidas e o oferecimento de informações sobre a dinâmica do parto como fundamentais para a diminuição de fantasias e ansiedade presentes nos envolvidos. Pode-se acrescentar que talvez se fossem repassadas orientações sobre a dinâmica do parto, bem como sobre os procedimentos realizados durante esse processo, eles não tivessem vivenciado o sentimento de medo e desespero diante dos movimentos dos médicos. Além disso, talvez tivesse amenizado a ansiedade desses pais, como assinala Carvalho (2003) de que a comunicação sobre o parto possibilita que os pais vivenciem mais tranquilamente o nascimento de seus filhos.

Brüggemann, Osis e Parpinelli (2007) evidenciaram em sua pesquisa que a expectativa negativa por parte dos profissionais da saúde sobre a presença de um acompanhante no parto tende a superação após a experiência. Essa transformação na percepção dos profissionais acontece por meio de um processo longo, mas já existente e que pode de alguma maneira contribuir para que orientações e esclarecimentos sejam mais bem prestados. Souza, Gaíva e Modes (2011) verificaram que para algumas instituições a presença do pai na sala de parto tem se constituído como uma possibilidade de humanização do parto.

Outro aspecto que merece atenção refere-se à idade gestacional em que se encontravam as mães no momento do parto. Os filhos de Cassiano e Emanuel nasceram a termo, no entanto, os demais partos foram pré-termos. De acordo com Bettiol, Barbieri e Silva (2010) parto pré-termo corresponde a todo nascimento que ocorre antes da trigésima sétima semana. Vale ressaltar que a idade gestacional considerada aqui é aquela relatada pelos participantes, podendo ou não corresponder com a informação real.
Apesar de estes nascimentos terem ocorrido prematuramente, somente Danilo trouxe conteúdos que enfatizavam tal prematuridade, de forma que Alessandro e Bernardo apenas comentaram, como se este fato fosse algo trivial ou esperado. Uma hipótese que pode ser lançada é de que o evento da prematuridade tenha se tornado tão significativo na vivência de Danilo devido sua esposa ter sido hospitalizada antes do parto e de seu filho ter permanecido por um período na Unidade de Terapia Intensiva Neonatal.

Para Costa, Ribeiro, Borba e Balieiro (2009) a hospitalização do bebê pré-termo implica em uma vivência de grande sofrimento para os pais, na medida em que evocam sentimentos de medo, tristeza, insegurança e também de esperança, sentimentos estes vivenciados por Danilo. Além disso, o nascimento prematuro faz com que os pais percam seus alicerces construídos na gestação, de forma que passam agora a situar-se no campo do desconhecido.

De maneira geral, acompanhar o nascimento do próprio filho vem sendo concebido como uma experiência significativa na vida de um homem, a qual muitas vezes não pode ser traduzida em palavras (Perdomini \& Bonilha, 2011).

\section{CONSIDERAÇÕES FINAIS}

A partir do presente estudo pôde-se vislumbrar o modo como os pais se prepararam para a participação na sala de parto. Verificou-se uma mobilização por parte deles pela busca de informações a respeito do evento pelo qual iriam passar. Assim, eles se utilizaram de diversos meios para entrar em contato com os aspectos envolvidos no nascimento, o que pode indicar maior interesse pelo advento do parto e também da gestação. No entanto, mesmo se preparando por meio de conhecimento sobre o assunto, essas informações não foram suficientes para garantir que eles se sentissem seguros.

No que se refere aos momentos que antecederam imediatamente o parto, verificou-se que os pais tiveram sentimentos particulares, bem como algumas reações físicas, como suar, aceleração dos batimentos cardíacos, entre outros. E, embora tenham vivenciado sentimentos particulares, todos entenderam como necessária a não expressão das emoções vividas a fim de que estas não fossem percebidas pela parturiente. 
A entrada na sala de parto foi entendida como impactante, correspondendo a um momento especial. Em relação à conduta que tiveram no momento do parto, encontrou-se que embora muitos sentimentos se fizeram presentes, eles foram sentidos de maneira ambivalente. Além disso, neste momento também houve a necessidade de não expressar os sentimentos.

Outro aspecto que chama a atenção diz respeito ao fato de que para os pais não é possível entender a sua vivência, de modo que pode ser apenas vivida. Assim, eles não conseguem nomear com precisão os sentimentos que permearam o nascimento de seus filhos, bem como não conseguem compreender as reações evocadas. Aqui, pode-se relacionar ao fato de não ser permitido ao homem expressar seus sentimentos como uma influência para que eles não conseguissem identificar o que sentiram durante o momento do nascimento dos filhos. Desse modo, por não poder entrar em contato com seu lado emocional, eles entenderam essa vivência como impossível de ser descrita, ao passo que é possível apenas vivenciá-la.

Quanto à postura adotada pelas instituições onde os partos foram realizados verificou-se que embora de maneira discreta, alguns profissionais forneceram orientações para os pais. No entanto, nenhuma preparação mais detalhada foi oferecida a eles. Isso pode ter contribuído para que o sentimento de ser um intruso estivesse presente, fazendo com que eles sentissem que, por vezes, estavam atrapalhando. Por outro lado, pode-se perceber que mesmo sendo detentores do direito de vivenciar aquele momento, os pais percebem a sua participação mais como fundamental para a parturiente, no sentido de que eles estão ali para auxiliá-las. Deve-se deixar claro, que este é um motivo importante, e que de fato, pesquisas comprovam que a presença de um acompanhante auxilia no processo de parturição. No entanto, esta pesquisa defende que este é um direito dos pais. Ainda sobre isso, por entenderem o seu papel como o de auxiliar nesse processo, é que os pais tenderam a reprimir seus sentimentos, talvez não se entregando o quanto desejariam àquela situação.

Por fim, o presente estudo não esgota as possibilidades de diálogos sobre o assunto. Da mesma forma, entende que a paternidade e suas várias formas de expressão merecem maior atenção por parte dos profissionais que trabalham nos locais que prestam apoio a esse público. Nesse sentido, faz uma chamada aos estudiosos para o desenvolvimento de novas pesquisas.

\section{REFERÊNCIAS}

Bardin, L. (2004). Análise de conteúdo (L. A. Reto e A. Pinheiro, Trads.). Lisboa: Edições 70.

Bettiol, H. Barbieri, M. A., \& Silva, A. A. M. (2010). Epidemiologia do nascimento pré-termo: Tendências atuais. Revista Brasileira de Ginecologia e Obstetrícia, 32, 57-60.

Bruggëmann, O. M., Osis, M. J. D., \& Parpinlli, M. A. (2007). Apoio no nascimento: Percepções de profissionais e acompanhantes escolhidos pela mulher. Revista de Saúde Pública, 41, 44-52.

Carvalho, M. L. M. (2003). Participação dos pais no nascimento em maternidade pública: Dificuldades institucionais e motivações dos casais. Cadernos de Saúde Pública, 19, 389-398.

Costa, S. A. F., Ribeiro, C. A., Borba, R. I. H., \& Balieiro, M. M. F. G. (2009). A experiência da família ao interagir com o recém-nascido prematuro no domicílio. Escola Anna Nery Revista de Enfermagem, 13, 741-749.

Espírito Santo, L. C., \& Bonilha, A. L. L. (2000). Expectativas, sentimentos e vivências do pai durante o parto e nascimento do seu filho. Revista Gaúcha de Enfermagem, 21, 87-109.

Freitas, C. V., Fernandes, L. D. S., \& Vaz, M. J. R. (2007). Percepção do acompanhante frente ao parto humanizado. Saúde Coletiva, 4, 46-50.

Lei n. 11.108, de 7 de abril de 2005. Portaria n. 2.418/GM. (2005, 2 de dezembro). Garante às parturientes o direito à presença de acompanhante durante o trabalho de parto, parto e pós-parto imediato, no âmbito do Sistema Único de Saúde - SUS. Brasília: Ministério da Saúde.

Maldonado, M. T., \& Dickstein, J. (2010). Nós estamos grávidos. São Paulo: Integrare.

Ministério da Saúde. Secretaria de Políticas de Saúde. Área Técnica de Saúde da Mulher. (2001). Parto, aborto e puerpério: Assistência humanizada à mulher. Brasília: Ministério da Saúde.

Motta, C. C. L., \& Crepaldi, M. A. (2005). O pai no parto e apoio emocional: A perspectiva da parturiente. Paidéia, 15, 105-118.

Nakano, A. M. S., Silva, L. A., Beleza, A. C. S., Stefanello, J., \& Gomes, F. A. (2007). O suporte durante o processo de parturição: A visão do acompanhante. Acta Paulista de Enfermagem, 20, 131-137.

Perdomini, F. R. I., Bonilha, A. L. L. (2011). A participação do pai como acompanhante da mulher no parto. Texto e Contexto Enfermagem, 20, 445-452.

Piccinini, C. A., Silva, M. R., Gonçalves, T. R., Lopes, R. S., \& Tudge, J. (2004). O envolvimento paterno durante a gestação. Psicologia: Reflexão e Crítica, 17, 303-314.

Raphael-Leff, J. (1997). Gravidez: A história interior (R. D. Pereira, Trad.). Porto Alegre: Artes Médicas.

Souza, T. G., Gaíva, M. A. M. \& Modes, P. S. S. A. (2011). A humanização do nascimento: Percepção dos profissionais de saúde que atuam na atenção ao parto. Revista Gaúcha de Enfermagem, 32, 479-486. 
Storti, J. P. L. (2004). O papel do acompanhante no trabalho de parto e parto: Expectativas e vivências do casal (Dissertação de mestrado). Universidade de São Paulo, Ribeirão Preto.

Tarnowski, K. S., Próspero, E. N. S., \& Elsen, I. (2005). A participação paterna no processo de humanização do nascimento: Uma questão a ser repensada. Texto e Contexto Enfermagem, 14, 103-108.

Tedesco, R. P., Maia Filho, N. L., Mathias, L., Benez, A. L., Castro, V. C. L., Bourroul, G. M. \& Reis, F. I. (2004). Fatores determinantes para as expectativas de primigestas acerca da via de parto. Revista Brasileira de Ginecologia e Obstetrícia, 26, 791-798.
Turato, E. (2003). Tratado da metodologia da pesquisa clínicoqualitativa: Construção teórico-epistemológica, discussão comparada e aplicação nas áreas de saúde e humanas. Petrópolis: Vozes.
Recebido: 05/09/2011

Última revisão: 07/05/2012

Aceito: $27 / 05 / 2012$ 